\title{
Rock weathering controls the potential for soil carbon storage at a continental scale
}

\author{
Eric W. Slessarev (iD) Oliver A. Chadwick (ID) Noah W. Sokol (D) \\ Erin E. Nuccio $($ ) Jennifer Pett-Ridge $\mathbb{C}$
}

Received: 19 July 2021 / Accepted: 24 September 2021 / Published online: 1 November 2021

(C) The Author(s) 2021

\begin{abstract}
As rock-derived primary minerals weather to form soil, they create reactive, poorly crystalline minerals that bind and store organic carbon. By implication, the abundance of primary minerals in soil might influence the abundance of poorly crystalline minerals, and hence soil organic carbon storage. However, the link between primary mineral weathering, poorly crystalline minerals, and soil carbon has not been fully tested, particularly at large spatial scales. To close this knowledge gap, we designed a model that links primary mineral weathering rates to the geographic distribution of poorly crystalline minerals across the USA, and then used this model to evaluate the effect of rock weathering on soil organic carbon. We found that poorly crystalline
\end{abstract}

Responsible Editor: Stuart Grandy.

Supplementary Information The online version contains supplementary material available at https://doi.org/10.1007/ s10533-021-00859-8.

E. W. Slessarev $(\bowtie) \cdot$ N. W. Sokol ·

E. E. Nuccio - J. Pett-Ridge $(\bowtie)$

Physical and Life Sciences Directorate, Lawrence

Livermore National Laboratory, Livermore, USA

e-mail: slessarev1@1lnl.gov

J. Pett-Ridge

e-mail: pettridge2@1lnl.gov

O. A. Chadwick

Department of Geography, University of California Santa

Barbara, Santa Barbara, USA minerals are most abundant and most strongly correlated with organic carbon in geographically limited zones that sustain enhanced weathering rates, where humid climate and abundant primary minerals cooccur. This finding confirms that rock weathering alters soil mineralogy to enhance soil organic carbon storage at continental scales, but also indicates that the influence of active weathering on soil carbon storage is limited by low weathering rates across vast areas.

Keywords Soil organic matter - Weathering - Soil mineralogy $\cdot$ Poorly crystalline minerals

\section{Introduction}

The majority of the terrestrial biosphere's carbon is stored belowground as soil organic carbon (SOC) (Jobbágy and Jackson 2000). Small changes in the relative size of the global SOC pool can influence atmospheric $\mathrm{CO}_{2}$ levels, and hence global climate (Conant et al. 2011; Minasny et al. 2017). However, in most soils, a significant fraction of SOC is associated with minerals that limit its rate of exchange with the atmosphere (Torn et al. 1997; Schmidt et al. 2011; Rasmussen et al. 2018a). One particularly important class of minerals that enhance accumulation of SOC are reactive, poorly crystalline minerals (PCMs) composed of $\mathrm{Al}$ and $\mathrm{Fe}$ (oxy) hydroxides (Torn et al. 
1997; Masiello et al. 2004). PCMs are produced in soil by weathering of rock-derived primary minerals. Primary mineral weathering thus ultimately controls the abundance of PCMs and associated SOC. Understanding the linkage between primary mineral weathering, PCMs, and SOC is important for predicting future changes in the global SOC pool.

Local studies have shown that PCMs are correlated with SOC stocks across soils of different ages, climates, and parent materials (Dahlgren et al. 1997; Torn et al. 1997; Chadwick et al. 2003; Masiello et al. 2004; Heckman et al. 2009; Rasmussen et al. 2018b). More expansive, continental scale data syntheses indicate that PCMs play a major role in SOC storage in humid climates (Rasmussen et al. 2018a; Kramer and Chadwick 2018; von Fromm et al. 2021). These studies relate PCMs to SOC; however, they have not specifically evaluated the role of primary mineral weathering in controlling PCM abundance. Here we expand on these studies by (1) specifying a quantitative relationship between primary mineral weathering rates and PCM abundance that accounts for both climate and the availability of readily weathered minerals, and (2) testing the role of primary mineral weathering in contributing to SOC storage at continental scales relevant to the global $\mathrm{C}$ cycle.

Primary mineral weathering rates, PCM stocks, and SOC storage are linked because PCMs are relatively transient weathering products (Fig. 1a). Studies of soil age gradients show that PCMs accumulate during the initial stages of weathering and then decline as primary minerals (e.g., feldspars) are exhausted and PCMs ripen into less reactive crystalline secondary minerals (e.g., phyllosilicate clays) (Torn et al. 1997; Masiello et al. 2004; Garcia Arredondo et al. 2019). Across rock types, PCMs are most abundant in soils formed from volcanic parent materials rich in feldspars and glass with feldspar-like composition (Heckman et al. 2009; Rasmussen et al. 2018b). Furthermore, studies of climate gradients show that PCMs are most abundant in humid climates, where the potential for weathering is highest (Dahlgren et al. 1997; Chadwick et al. 2003).

Taken together, these facts indicate that primary mineral weathering rates determine the abundance of PCMs. PCMs disappear over time as they ripen into more crystalline minerals; consequently, active weathering is required to maintain soil PCMs. More specifically, we propose that a simple quantitative relationship should link PCMs to the weathering rate in most contexts. If PCMs are produced $(P$, in units of $\left.\mathrm{MT}^{-1}\right)$ at a rate proportional to the weathering rate $(W$, $\mathrm{MT}^{-1}$ ) and are transformed into crystalline minerals at a rate described by a first order constant $\left(k, \mathrm{~T}^{-1}\right)$, then at steady state PCM abundance will be proportional to the weathering rate:

$\frac{d P C M}{d t}=P-P C M * k ; \quad P \propto W$

$P C M_{\text {steady state }}=\frac{P}{k} ; \quad \therefore P C M_{\text {steady state }} \propto W$

Based on this simple set of relationships, PCMs should be most abundant where primary mineral weathering is actively occurring - and by implication, it is in these environments that PCMs have the greatest potential to influence soil carbon storage (Wang et al. 2018; Rasmussen et al. 2018b). Notably, this relationship emphasizes the weathering rate as the proximate control on PCM stocks, rather than the weathering state (i.e., time integrated loss of elements or minerals). The weathering state is not a suitable general proxy for PCM abundance because soils can exhibit the same degree of chemical depletion even if mineral transformations are occurring at vastly different rates due to differences in climate and parent material. By contrast, the weathering rate is directly related to the process of PCM formation, and hence we expect that it is more closely correlated with PCM abundance.

Assuming that PCMs and weathering rates are closely linked, it follows that PCM abundance should depend on the major factors that influence weathering rates. Climate is one major factor influencing primary mineral weathering: mineral dissolution rates in the field are correlated with soil water fluxes across several orders of magnitude (Maher 2010; Yu and Hunt 2017). This relationship reflects the dependence of weathering on solute transport in percolating water (Maher 2010), and also the effect of water availability on biological productivity, which supplies acidity that drives weathering reactions (Richter and Billings 2015). Geologic factors provide a second major control on weathering. Weathering rates are reduced in old, low-relief landscapes where primary minerals are depleted during soil development (Slessarev et al. 2019). This suggests that regions where both climate and primary mineral availability favor weathering are limited in extent (Fig. 1b, c). We term these regions 
a

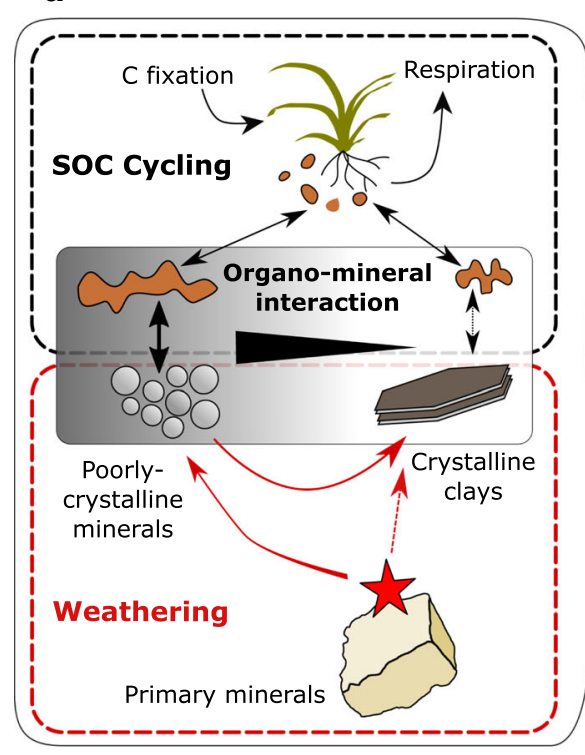

Fig. 1 Weathering, poorly crystalline minerals, and soil organic carbon across scales. a Conceptual rendering at the mineral scale: weathering of primary minerals to poorly crystalline minerals (PCMs) favors strong organo-mineral interactions and

where wet climate and abundant primary minerals cooccur "enhanced weathering zones" and hypothesize that they are dominant - but geographically limitedsites of PCM formation and SOC accumulation at continental scales. It is the presence of these enhanced weathering zones that explains the broad correlation between PCMs and SOC in humid climates. However, in humid regions outside of enhanced weathering zones, we hypothesize that the accumulation of PCM's and associated SOC is limited by the scarcity of readily weathered primary minerals. b

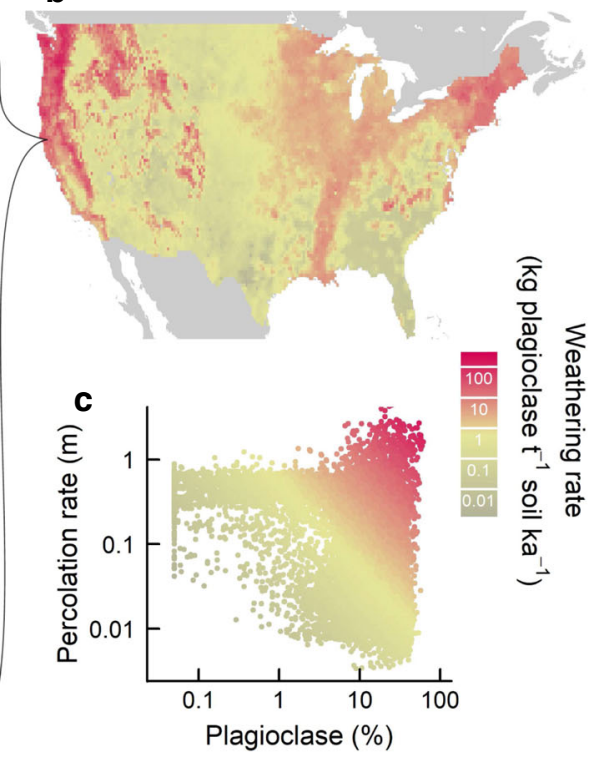

carbon accumulation. b Modeled weathering rates across the conterminous United States (see "Methods"). c Modeled weathering rates depend on percolation $\left(\mathrm{m} \mathrm{y}^{-1}\right)$ and primary minerals (\% plagioclase feldspar)

To test this hypothesis, we combined three regional databases (Table 1) using a mechanistically-informed statistical model that linked PCM abundance to the two key factors controlling weathering-climate and primary minerals-across the conterminous United States. We then used this model to gauge the relationship between PCMs and SOC storage in enhanced weathering zones, which we operationally defined as geographic regions where wet climate and abundant primary minerals co-occur.

Table 1 Data sources used in this analysis

\begin{tabular}{|c|c|c|c|}
\hline Variables & Dataset & Type & References \\
\hline $\begin{array}{l}\text { Major elementals, quantitative } \\
\text { mineralogy }\end{array}$ & $\begin{array}{l}\text { US Geological Survey North American Soil Geochemical } \\
\text { Landscapes Project (NASGLP) }\end{array}$ & Points & Smith et al. (2014) \\
\hline $\begin{array}{l}\mathrm{NH}_{4} \text {-oxalate extractable } \mathrm{Al} \text { and } \\
\mathrm{Fe} \text {, total organic } \mathrm{C}\end{array}$ & $\begin{array}{l}\text { National Cooperative Soil Survey (NCSS) Soil } \\
\text { Characterization Database }\end{array}$ & Points & $\begin{array}{l}\text { (http://ncsslabdatamart.sc. } \\
\text { egov.usda.gov/) }\end{array}$ \\
\hline Total organic $\mathrm{C}$ & Rapid Carbon Assessment database (RaCA) & Points & Wills et al. (2014) \\
\hline Percolation $(\mathrm{Q})$ & USGS monthly water balance model & Gridded & $\begin{array}{l}\text { McCabe and Wolock } \\
\text { (2011) }\end{array}$ \\
\hline
\end{tabular}

Data used were the most recent versions of each database as of November 2020 


\section{Materials and methods}

\section{Methods overview}

To develop the model linking PCM abundance to weathering, we estimated weathering rates based on an empirical relationship between silicate weathering kinetics and average soil water fluxes (Maher 2010; Yu and Hunt 2017). Using this empirical relationship, we estimated weathering rates for plagioclase feldspar, which we used as a proxy for the broader suite of primary minerals because it is one of the most abundant and readily weathered primary silicates in soils and a precursor for Al-rich PCMs.

This approach required two inputs: (1) an estimate of the percolation flux through the soil, which we obtained from the US Geological Survey (USGS) monthly water balance model (McCabe and Wolock 2011); and (2) an estimate of plagioclase feldspar abundance, which we obtained by interpolating quantitative mineralogy observations from the USGS North American Soil Geochemical Landscapes Project (NASGLP) across the conterminous United States (Smith et al. 2014). We related the plagioclase weathering rate to observed PCM abundance measured via $\mathrm{NH}_{4}$-oxalate extraction and averaged over whole soil profiles (sampled to $100 \mathrm{~cm}$ or contact with parent material) using data reported in the US National Cooperative Soil Survey (NCSS) Soil Characterization Database (Table 1) (http://ncsslabdatamart.sc. egov.usda.gov/).

Following this initial analysis, we used additional inputs from the NASGLP database to expand our model to a broader set of factors: dependence of $\mathrm{Fe}$ $\mathrm{PCMs}$ on total $\mathrm{Fe}$, and the potential contribution of $\mathrm{Al}-$ and Fe-rich secondary minerals to PCMs. We expanded the model by formulating a pair of statistical relationships linking oxalate extractable $\mathrm{Al}$ and $\mathrm{Fe}$ to primary, secondary, and total $\mathrm{Al}$ and $\mathrm{Fe}$ pools, fitting the data with quantile regressions ("Statistical model of PCMs").

Next, to evaluate the strength of the relationship between PCMs and SOC, we defined geographic domains based on climate and primary mineral availability. Within each domain, we computed spatially-weighted Pearson's correlation coefficients ( $r$ ) between PCMs and SOC ("Correlation analysis"), aggregating the total PCM pool as a molar-weighted $\operatorname{sum}(\mathrm{Al}+1 / 2 \mathrm{Fe})$. We also evaluated the sensitivity of our conclusions to spatial bias by repeating the correlation analysis with a second database of SOC concentrations, the Rapid Carbon Assessment (RaCA) (Wills et al. 2014), using the statistical model to predict PCMs because this database did not include PCM measurements. All calculations were performed in R (R Core Team 2020), with spatial operations using the "raster" and "rgdal" packages (Bivand et al. 2020; Hijmans 2020).

Soil profile data

We obtained point estimates of PCM abundance by using $\mathrm{NH}_{4}$-oxalate extractable $\mathrm{Al}$ and $\mathrm{Fe}$ from the NCSS database, and we obtained SOC data from both the NCSS and RaCA databases. $\mathrm{NH}_{4}$-oxalate extracts poorly crystalline oxyhydroxide phases of $\mathrm{Al}$ (principally allophane, imogolite, and nano-crystalline gibbsite (Dahlgren 2015)) and Fe (e.g., ferrihydrite and nano-crystalline goethite (Schulze 2015)). This method is not entirely selective, in that it can also extract $\mathrm{Al}$ and $\mathrm{Fe}$ from crystalline aluminosilicates and $\mathrm{Fe}(\mathrm{II})$-bearing minerals (Dahlgren 2015). We considered this "background" contribution due to the nonselectivity of $\mathrm{NH}_{4}$-oxalate extraction when constructing statistical models (see "Statistical model of PCMs").

We summarized soil profile data by computing depth-weighted averages of $\% \quad \mathrm{NH}_{4}$-oxalate extractable $\mathrm{Al}$ and $\mathrm{Fe}$ and \% SOC for individual soil profiles to a depth of $100 \mathrm{~cm}$, or to the depth of the lowermost $\mathrm{C}, \mathrm{AC}$, or $\mathrm{BC}$ horizon if the profile terminated above a depth of $100 \mathrm{~cm}$. The resulting dataset included 4,019 soil profiles from the NCSS database with both $\mathrm{SOC}$ and $\mathrm{NH}_{4}$-oxalate extraction data and 4,027 profiles from RaCA with SOC data (see Supplementary Material for detailed methods related to soil profile calculations).

\section{Environmental data}

We obtained values for the average water percolation flux from the USGS monthly water balance data product (McCabe and Wolock 2011). This data product includes monthly estimates of "runoff", defined as water in excess of evaporative demand and available soil water storage, which we treat as synonymous with percolation (discounting net loss of water from overland flow). The monthly water balance 
model is parametrized using high-resolution climate data interpolated from weather stations across the conterminous United States (Prism Climate Group, Oregon State University 2011). Percolation values were averaged for the period 1980-2015. To define arid and humid climates when analyzing subsets of the data, we used mean annual precipitation (MAP) and potential evapotranspiration (PET) values associated with the water balance model to identify regions where MAP $<$ PET (arid climates) and MAP $\geq$ PET (humid climates).

We assigned quantitative mineralogy and major element concentrations to soil profiles from the NCSS and RaCA databases by spatially interpolating values from the USGS NASGLP soil mineralogy database. The NASGLP database only includes quantitative mineralogy data from a composite of the soil A horizon and from deeper in the soil column (typically 80-100 cm) (Smith et al. 2014). We determined that the mineralogy values of surface and deep samples were similar relative to the range of values reported across the conterminous United States, and so we averaged the two values to create a single set of mineralogy estimates. Where mineralogy values were below detection, we substituted values equal to one half of reported detection limits (Smith et al. 2014). We then associated these values with each NCSS or RaCA soil profile by identifying all NASGLP observations within $50 \mathrm{~km}$ of the profile. These mineralogy observations were then used to assign mineralogy and elemental estimates to the profile using inverse distance weighting, where weights $\left(\mathrm{w}_{\mathrm{i}}\right)$ were obtained from the distance between the profile and the NASGLP observations $\left(\mathrm{d}_{\mathrm{i}}\right)$ using the formula:

$w_{i}=\frac{\frac{1}{d_{i}^{2}}}{\sum_{i=1}^{n} \frac{1}{d_{i}^{2}}}$

Weights were then used to obtain weighted-average values for each profile. To create continuous maps derived from soil mineralogy (e.g., Fig. 1), this same process was repeated substituting a regular grid of points at a 15 arc-minute resolution. Individual pixels in each map $(n=13,010)$ thus represent point estimates at the center of each cell, with climate data obtained by extracting from the USGS monthly water balance or PRISM grids and mineralogy data obtained by inverse distance weighting of neighboring NASGLP points.
Estimating weathering rates

We used an empirical relationship between climate and weathering kinetics (Yu and Hunt 2017) to obtain an expression for silicate weathering rates as a function of climate. This empirical relationship ignores the effects of temperature on weathering, but it explains observed variation in weathering rates across several orders of magnitude (Yu and Hunt 2017). The weathering kinetic constant for plagioclase feldspar $\left(\mathrm{R}_{\mathrm{b}}, \mathrm{y}^{-1}\right)$, was obtained from Eq. 4 (Yu and Hunt 2017):

$\mathrm{R}_{\mathrm{b}}=0.0001 *(\mathrm{Q})^{0.9698}$

With Q equal to the percolation rate from the USGS monthly water balance model, in units of meters of water per year. To obtain plagioclase feldspar weathering rates in soil in units of $\mathrm{kg}$ plagioclase $\mathrm{t} \mathrm{soil}^{-1}$ $\mathrm{ka}^{-1}$, we multiplied $\mathrm{R}_{\mathrm{b}}$ (in units of $\mathrm{ka}^{-1}$ ) by the mass fraction of plagioclase obtained from the NASGLP dataset (in units of $\mathrm{kg} \mathrm{t}^{-1}$ ).

Defining mineral pools

Before fitting statistical models to predict PCM abundance, we divided the total $\mathrm{Al}$ and total $\mathrm{Fe}$ estimates obtained from the NASGLP dataset into generalized primary and secondary mineral pools. In practice, the primary mineral pool excluded primary phyllosilicates (e.g., biotite) which were not identifiable from the data, and consisted of feldspar minerals, with all residual minerals assigned to an approximated secondary mineral pool. We excluded hornblende and amphibole, which were only detected in a small number of the samples in the NASGLP dataset $(<16 \%)$. Consequently, detailed data for Fe-bearing minerals were not available, and the total Fe pool was partitioned using feldspar content to infer the degree of weathering (see below). Our estimates should thus be considered generalized or proxies for total primary mineral content, particularly for Fe.

To estimate total feldspar Al, we first divided total plagioclase feldspar into albite $\left(\mathrm{NaAlSi}_{3} \mathrm{O}_{8}\right)$ and anorthite $\left(\mathrm{CaAl}_{2} \mathrm{Si}_{2} \mathrm{O}_{8}\right)$ fractions using the following approach: (1) total plagioclase was assumed to be standard oligoclase (80\% albite, $20 \%$ anorthite); (2) the sodium content of the oligoclase pool was calculated; (3) if total \% $\mathrm{Na}$ in the sample was less 
than the $\mathrm{Na}$ in oligoclase, albite content was recalculated so that the albite content equaled the $\mathrm{Na}$ content in molar equivalents; (4) if albite was recalculated, anorthite was also recalculated by subtracting the mass of albite from the mass of total plagioclase. We then calculated the total $\mathrm{Al}$ in feldspars by summing $\mathrm{Al}$ in albite and $\mathrm{Al}$ in anorthite, plus additional $\mathrm{Al}$ contained in $\mathrm{K}$-feldspar $\left(\mathrm{KAlSi}_{3} \mathrm{O}_{8}\right)$. To estimate secondary $\mathrm{Al}$, we subtracted our estimate of primary $\mathrm{Al}(\mathrm{Al}$ in feldspars) from the total $\mathrm{Al}$ concentration reported in the NASGLP database. If primary $\mathrm{Al}$ exceeded total $\mathrm{Al}(<1 \%$ of the data), then primary $\mathrm{Al}$ was set equal to total $\mathrm{Al}$, and secondary $\mathrm{Al}$ equaled zero. To partition Fe into primary and secondary pools, we assumed that transformation of primary $\mathrm{Al}$ and primary $\mathrm{Fe}$ into secondary phases is broadly correlated. Primary $\mathrm{Fe}$ was calculated as $\mathrm{Fe}_{\text {pri }}=\mathrm{Fe}_{\text {tot }} *\left(\mathrm{Al}_{\text {pri }} / \mathrm{Al}_{\text {tot }}\right)$, where $\mathrm{Fe}_{\text {pri }}$ and $\mathrm{Al}_{\text {pri }}$ are the primary $\mathrm{Fe}$ and $\mathrm{Al}$ pools and $\mathrm{Fe}_{\text {tot }}$ and $\mathrm{Al}_{\text {tot }}$ are the total $\mathrm{Fe}$ and $\mathrm{Al}$ pools. This approach ensured that $\mathrm{Fe}_{\text {pri }}$ and secondary $\mathrm{Fe}\left(\mathrm{Fe}_{\mathrm{sec}}\right)$ added up to equal total $\mathrm{Fe}$.

\section{Statistical model of PCMs}

To model PCM abundance, we used quantile regression (Koenker and Bassett 1978). Quantile regression allowed us to fit linear models to the data while accommodating strongly heteroskedastic errors. We fit the median of the data to generate predictions for PCM abundance, but also fit the first and third quartiles of the data to quantify the relative strength of primary versus secondary minerals in predicting PCMs across a range of PCM abundance.

We specified a model structure to estimate $\mathrm{NH}_{4}$ oxalate extractable $\mathrm{Al}$ and $\mathrm{Fe}\left(\mathrm{Al}_{\text {ox }}\right.$ and $\left.\mathrm{Fe}_{\text {ox }}\right)$ based on the hypothetical co-dependence of these PCM pools on climate and mineral abundance. The model for each element consisted of three terms: (1) a term representing weathering combining climate $(\mathrm{Q}, \mathrm{mm})$ and the amount of the corresponding element in primary minerals; (2) a weathering term combining climate and the amount of the corresponding element in secondary minerals; and (3) a term linking $\mathrm{Al}_{\mathrm{ox}}$ and $\mathrm{Fe}_{\mathrm{ox}}$ to total soil $\mathrm{Al}$ and $\mathrm{Fe}$. This final term functioned as an intercept for the model to account for "background" $\mathrm{Al}$ and $\mathrm{Fe}$ that might be extractable from crystalline minerals even when weathering rates and PCM abundance are zero; hence no separate intercept term was included. This ensured some realistic bounds on the predicted values of $\mathrm{Fe}_{\mathrm{ox}}$ and $\mathrm{Al}_{\mathrm{ox}}$ : when total $\mathrm{Al}$ and $\mathrm{Fe}$ equaled zero then $\mathrm{Al}_{\mathrm{ox}}$ and $\mathrm{Fe}_{\mathrm{ox}}$ equaled zero. Equations 5-6 show the model form, where $\mathrm{a}_{1}-\mathrm{a}_{3}$ and $b_{1}-b_{3}$ are fitted coefficients.

$$
\mathrm{Al}_{\text {ox }}=\mathrm{a}_{1} * \mathrm{Al}_{\text {pri }} * \mathrm{Q}+\mathrm{a}_{2} * \mathrm{Al}_{\text {sec }} * \mathrm{Q}+\mathrm{a}_{3} * \mathrm{Al}_{\text {tot }}
$$

$\mathrm{Fe}_{\mathrm{ox}}=\mathrm{b}_{1} * \mathrm{Fe}_{\text {pri }} * \mathrm{Q}+\mathrm{b}_{2} * \mathrm{Fe}_{\mathrm{sec}} * \mathrm{Q}+\mathrm{b}_{3} * \mathrm{Fe}_{\text {tot }}$

Quantile regressions were fit using the R package "quantreg" (Koenker 2018). When fitting the models, data were weighted to ensure that densely sampled regions of the NCSS dataset were not overrepresented. Weights were calculated based on the local density of observations, which we defined by counting the number of NCSS profiles (n) within 1 decimal-degree grid cells defined by each integer value of latitude and longitude. Weights were then obtained by assigning the value $(1 / n)$ to each profile based on the grid cell it occupied and then dividing by the sum of $1 / \mathrm{n}$ across all profiles.

The uncertainty associated with model parameters was estimated by bootstrap resampling the data in 1 decimal degree grid cells. In this blocked-bootstrap approach, grid cells were sampled with replacement and parameters were obtained from the resampled data 10,000 times. Because grid cells rather than individual soil profiles were randomized, this approach propagated uncertainty related to the spatial dependence into the confidence intervals. In all cases, confidence intervals were obtained from the bootstrap replicates using the BCa method in the R package "boot" (Davison and Hinkley 1997; Canty and Ripley 2020).

To generate estimates of PCMs derived from primary minerals versus secondary minerals, we recalculated predictions after replacing the primary $\mathrm{Al}$ and Fe pools with zero values, and then subtracted these predicted values from the predicted values of the original model. This difference was taken to represent the contribution of primary minerals to PCMs across space. This process was repeated after setting secondary pools to zero to obtain the secondary mineral contribution. We did not reset the total $\mathrm{Al}$ and $\mathrm{Fe}$ pools in this calculation, and so the "background" contribution linked to total $\mathrm{Al}$ and $\mathrm{Fe}$ is not represented.

To validate the statistical model, we divided the data into two broad geographic zones and cross 
validated by training the model on each zone and testing on the other (Roberts et al. 2017). We defined two zones that each encompassed a range of soil primary mineral contents and climate conditions. Zone 1 included the Western US and part of the Southeastern US: all observations west of the meridian $105^{\circ} \mathrm{W}$ and north of $35^{\circ} \mathrm{N}$, and all observations west of $90^{\circ} \mathrm{W}$ and south of $35^{\circ} \mathrm{N}$. Zone 2 included all remaining observations, encompassing the Central and Eastern US. We evaluated model performance during cross validation by comparing the $\mathrm{R}$-squared value between predictions and observations and the root-meansquared error (RMSE) in model training and testing contexts.

\section{Correlation analysis}

We quantified the strength of the correlation between PCMs and SOC in different geographic domains by calculating Pearson's correlation coefficient on logtransformed variables. We used a $\log$ transformation because it linearizes the relationship between PCMs and SOC (Supplementary Fig. 1). To account for clustering in the data, we computed weighted correlations after dividing the data into spatial blocks, with weights obtained in the same way described above for the regression analysis. We computed weighted correlations using the R package "wCorr" (Emad and Bailey 2017). We also constructed confidence intervals for the spatially-blocked data using bootstrap resampling, using the same protocol employed for the regression analysis. To visualize correlations while accounting for clustering, we resampled the data with replacement (sample size $=4,019$ ) with sampling probabilities obtained in the same way described above.

To evaluate the correlation between PCMs and SOC across a range of environmental contents, we subdivided the data into three geographic domains based on climate and primary mineral availability: (1) a "water-limited" domain where mean annual potential evapotranspiration (PET) exceeded mean annual precipitation (MAP); (2) a "weathered" domain where $\mathrm{MAP} \geq \mathrm{PET}$ and feldspar Al abundance was less than or equal to the median value for the conterminous United States (1.7\%); and (3) "enhanced weathering zones", where MAP $\geq$ PET and feldspar Al abundance was greater than $1.7 \%$. Quantile boundaries were computed across the conterminous US using estimates at the 13,081 grid points used for generating maps of soil mineralogy (see Environmental data section above). We further analyzed the data after dividing them into four groups based on quartiles. The values $0.83 \%, 1.70 \%$, and $2.91 \%$ were the first, second and third quartiles respectively. Data were binned using the minimum and maximum primary $\mathrm{Al}$ values $(0.005 \%$ and $9.16 \%)$ and the quartile values to define boundaries between bins, with intervals open on the left and the final interval including the maximum value. We then computed correlations across the binned subsets of the data within a limited climate domain, where MAP $\geq$ PET and MAP-PET $<1 \mathrm{~m}$.

\section{Results}

Primary mineral weathering rates predict poorly crystalline mineral abundance

Our estimate of the plagioclase weathering rate was positively related to observed PCM abundance (Fig. 2). This relationship was noticeably stronger for $\mathrm{Al}$ (Fig. 2a) than for Fe (Fig. 2b), reflecting the fact that plagioclase-which does not contain $\mathrm{Fe}$ - can only provide a rough proxy for $\mathrm{Fe}$ weathering. Additionally, Fe weathering is complicated by Fe's redox-active chemistry, which enables reductive dissolution of crystalline secondary minerals and reprecipitation as PCMs (Ginn et al. 2017; Barcellos et al. 2018; Chen et al. 2019). To address these complexities, we formulated the model as a pair of statistical relationships for $\mathrm{Al}$ and $\mathrm{Fe}$ which accounted for contributions to PCMs from both primary mineral weathering and transformation of secondary minerals ("Statistical model of PCMs", Table 2). When constructing the models, data were weighted inversely to the local spatial density of observations, so that heavily sampled regions did not dominate the fitting process (see "Methods"). The statistical model performed similarly for $\mathrm{Al}$ and $\mathrm{Fe}$, and explained $50 \%$ of the variation in total PCM abundance (Supplementary Fig. 2). We cross validated the model by splitting the data into two geographic zones (Supplementary Fig. 3). The model achieved similar R-squared and RMSE values in training and testing contexts (Supplementary Fig. 4) and yielded similar coefficient estimates (Supplementary Table 1). Strong performance in these cross validation tests indicates that the 

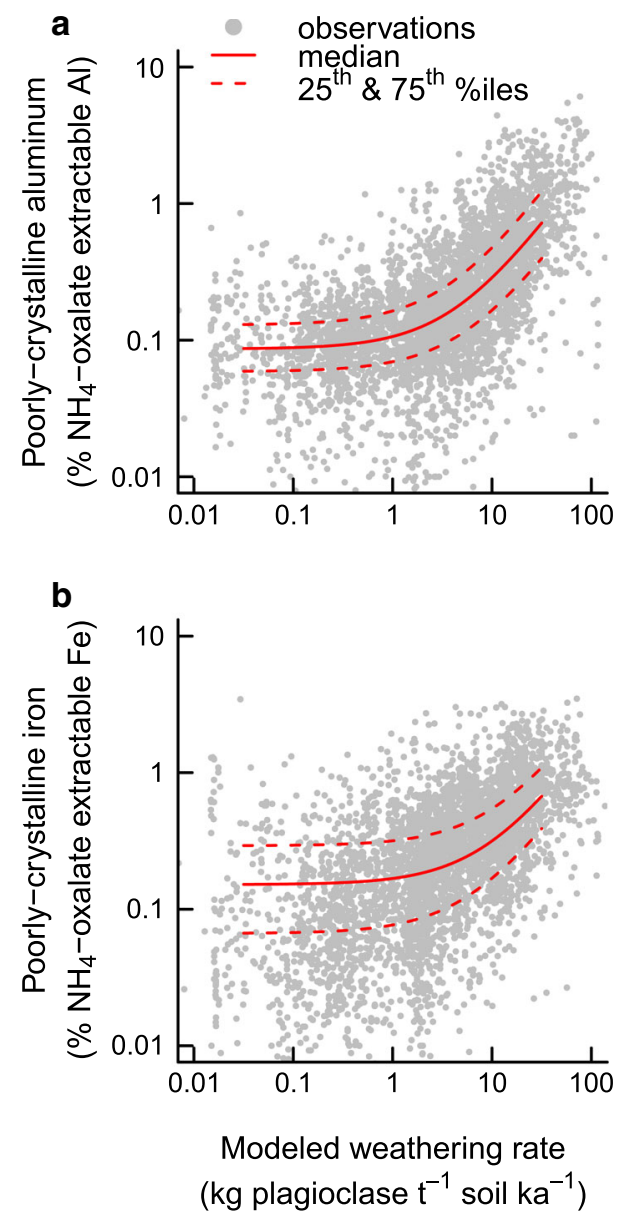

Fig. 2 Weathering rates predict concentrations of poorly crystalline minerals. Poorly crystalline $\mathrm{Al}$ (a) and $\mathrm{Fe}$ (b) versus estimated plagioclase weathering rates. Points are depthweighted averages of 4,019 individual soil profiles from the National Cooperative Soil Survey database, with averages calculated to $100 \mathrm{~cm}$ or the bottom of the lowermost $\mathrm{C}$ horizon. Red lines show quantile regression fits to the data at the 25th, 50th, and 75th percentiles

model describes general relationships between PCM stocks, climate, and the concentrations of readilyweathered primary minerals versus secondary minerals in soil. Furthermore, the relative magnitude of the model coefficients indicates that primary minerals (e.g., feldspars) are more strongly associated with PCMs than secondary minerals (e.g., phyllosilicates, Fig. 3). This supports our hypothesis that naturally occurring enhanced weathering zones with a high abundance of primary minerals are dominant sites of PCM formation and feature large PCM stocks.
Table 2 Quantile regression statistics

\begin{tabular}{|c|c|c|}
\hline Coefficient & Value & $95 \% \mathrm{CI}$ \\
\hline \multicolumn{3}{|c|}{$\mathrm{Al}_{\mathrm{ox}}=\mathrm{a}_{1} * \mathrm{Q} * \mathrm{Al}_{\mathrm{pri}}+\mathrm{a}_{2} * \mathrm{Q} * \mathrm{Al}_{\mathrm{sec}}+\mathrm{a}_{3} * \mathrm{Al}_{\mathrm{tot}}$} \\
\hline $\mathrm{a}_{1}$ & $11.0^{*} 10^{-5}$ & {$\left[7.9^{*} 10^{-5}, 13.9 * 10^{-5}\right]$} \\
\hline$a_{2}$ & $2.8 * 10^{-5}$ & {$\left[2.2^{*} 10^{-5}, 4.0^{*} 10^{-5}\right]$} \\
\hline$a_{3}$ & $1.1 * 10^{-2}$ & {$\left[0.9 * 10^{-2}, 1.3 * 10^{-2}\right]$} \\
\hline \multicolumn{3}{|c|}{$\mathrm{Fe}_{\mathrm{ox}}=\mathrm{b}_{1} * \mathrm{Q} * \mathrm{Fe}_{\mathrm{pri}}+\mathrm{b}_{2} * \mathrm{Q} * \mathrm{Fe}_{\mathrm{sec}}+\mathrm{b}_{3} * \mathrm{Fe}_{\mathrm{tot}}$} \\
\hline $\mathrm{b}_{1}$ & $14.8 * 10^{-5}$ & {$\left[7.2 * 10^{-5}, 19.7 * 10^{-5}\right]$} \\
\hline$b_{2}$ & $5.7 * 10^{-5}$ & {$\left[2.3 * 10^{-5}, 8.6 * 10^{-5}\right]$} \\
\hline $\mathrm{b}_{3}$ & $4.6^{*} 10^{-2}$ & {$\left[3.9 * 10^{-2}, 5.4 * 10^{-2}\right]$} \\
\hline
\end{tabular}

Values are fitted coefficients for each model, fitting the 50th quantile. The $95 \%$ confidence intervals were obtained from spatially blocked bootstrapping (see "Methods"). The variable $\mathrm{Q}$ was in units of $\mathrm{mm}$ when fitting the model

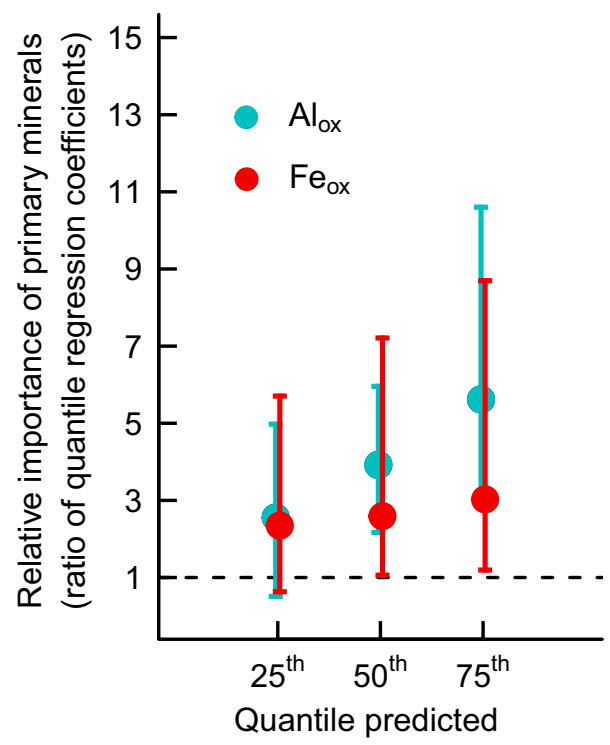

Fig. 3 Contribution of primary minerals to predicting PCMs. Points show the ratio of quantile regression coefficients for different prediction quantiles (the 25th, 50th, and 75th quantiles). Blue points show the ratio for quantile regression models of oxalate extractable $\mathrm{Al}\left(\mathrm{a}_{1} / \mathrm{a}_{2}\right.$, Eq. 5-see "Methods"), and red points show the ratio for oxalate extractable $\mathrm{Fe}$ $\left(b_{1} / b_{2}\right.$, Eq. 6). The dashed line indicates a ratio of 1 where primary and secondary minerals are equally important for predicting PCMs. Error bars show 95\% confidence intervals obtained from 10,000 bootstrap samples using a spatiallyblocked approach (see "Methods") 
Soil carbon is concentrated in enhanced weathering zones

We hypothesized that enhanced weathering zones are a dominant site of SOC storage at continental scales because they feature PCM-rich soils. We tested this hypothesis by evaluating the strength of the correlation between PCMs and SOC inside versus outside of the enhanced weathering zones: if the elevated PCMs in these zones are accompanied by elevated SOC, this implies stronger correlation. To evaluate the strength of the relationship between PCMs and SOC in the enhanced weathering zones, we first defined three geographic domains (Fig. 4a) based on climate and primary mineral availability: (1) a "water-limited" domain where mean annual potential evapotranspiration (PET) exceeds mean annual precipitation (MAP); (2) a "weathered" domain where MAP $\geq$ PET and feldspar Al abundance is less than or equal to the median value for the conterminous United States (1.7\%); and (3) "enhanced weathering zones", where MAP $\geq$ PET and feldspar Al abundance is greater than $1.7 \%$.

We estimated the correlation between PCMs and SOC across weathering domains, and found that PCMs and SOC were most strongly correlated in enhanced weathering zones, which included coastal and montane regions in the western USA and in the post-glacial landscapes of the northeastern and upper mid-western USA (Fig. 4b; $r=0.60 ; 95 \%$ CI [0.53, 0.66]). These are regions where primary minerals are abundant due to geologic factors: high relief and volcanism in the western USA, and glaciation in the northeastern and mid-western USA (Slessarev et al. 2019). PCMs and SOC were not as strongly correlated in the weathered domain (Fig. 4c; $r=0.40 ; 95 \%$ CI [0.21, 0.53]), which included low-relief, humid regions of the central and southeastern USA where the climatic potential for weathering is high but plagioclase is depleted. The correlation between PCMs and SOC was also relatively weak in the water-limited domain that encompasses much of the western USA (Fig. 4d; $r=0.42 ; 95 \%$ CI $[0.28,0.52])$, reflecting the fact that PCMs are not abundant in arid climates, and thus other factors (e.g., exchangeable $\mathrm{Ca}^{2+}$ (Rowley et al. 2018; Rasmussen et al. 2018a; von Fromm et al. 2021)) likely explain continental-scale variation in SOC in drier regions.
We used the statistical model to attribute PCMs to primary mineral weathering versus secondary mineral transformation across space (Fig. 4e). The model indicated that primary minerals are a major source of PCMs in enhanced weathering zones, but a minor source of PCMs in the weathered domain. Other factors may be responsible for the presence of PCMs in weathered soils, including reductive transformation of crystalline Fe secondary minerals into less ordered forms (Ginn et al. 2017; Barcellos et al. 2018; Chen et al. 2019), or resistance of some PCMs against transforming into more crystalline clay minerals (Coward et al. 2018). Along with the correlation analysis (Fig. 4b-d), this result shows that the relationship between PCMs and SOC is strongest in minimally weathered soils where weathering drives PCM formation.

Evaluating the correlation between PCMs and SOC is complicated because direct observations of PCMs are not evenly distributed across space (Supplementary Fig. 5). This reflects the fact that PCMs are surveyed because they are a diagnostic feature of particular soil types (e.g., volcanic ash soils) and are measured less commonly where these soil types are absent. To account for this bias, we repeated the correlation analysis with a second database of SOC measurements which was collected evenly across the conterminous US (the Rapid Carbon Assessment (Wills et al. 2014)), using our statistical model to predict PCM abundance because this database did not include PCM measurements. We confirmed that the correlation between predicted PCMs and SOC was stronger in enhanced weathering zones than in weathered soils across these data (Supplementary Fig. 6). We also evaluated the correlation between PCMs and SOC after dividing the data into a larger number of weathering domains, while also excluding samples from high rainfall environments that fall disproportionately in the enhanced weathering zones and consequently might bias our result (Supplementary Fig. 7). This analysis confirmed that PCMs explain progressively more variation in SOC as primary mineral abundance increases, even when high rainfall environments are excluded. 
a
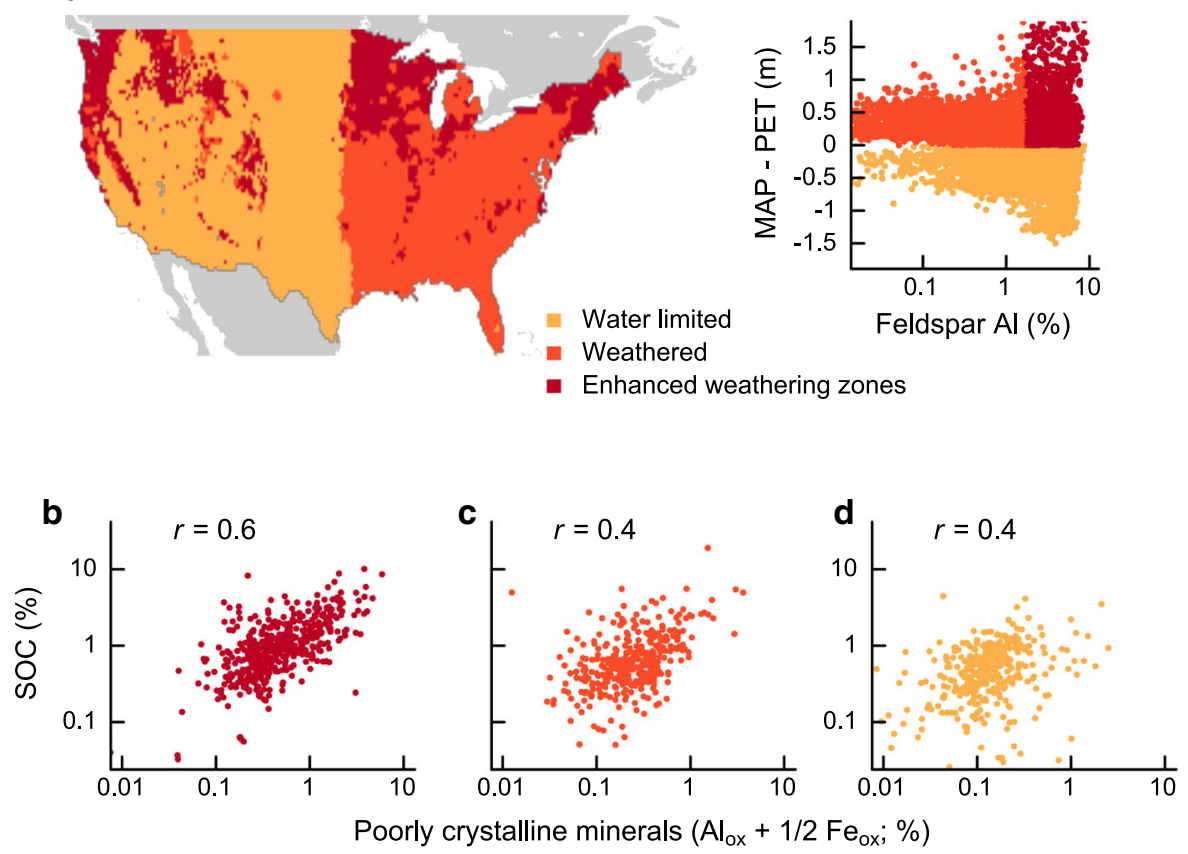

e

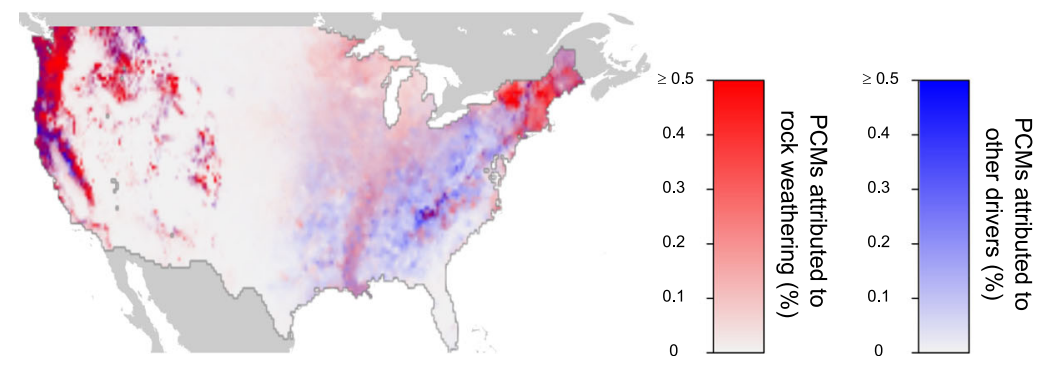

Fig. 4 Correlation between SOC and PCMs across weathering domains. a map of weathering domains and boundaries between domains, with water availability (MAP-PET) plotted versus \% feldspar Al. b-d depth-weighted average \%SOC versus PCM abundance in enhanced weathering zones, weathered soils, and water-limited soils. To account for clustering, points represent a random sample of 4,019 observations with sampling

\section{Discussion}

We investigated the role of primary mineral weathering in generating PCMs and enhancing SOC storage. We found that: (1) PCMs are most abundant in regions that contain both a wet climate and an abundant supply of primary minerals; and (2) PCMs are most strongly correlated with SOC within these same environments. Our results are consistent with previous work showing that PCMs and SOC are most strongly correlated in probabilities weighted inversely to spatial density (see "Methods"). Weighted Pearson's correlation coefficient $(r)$ is shown for each domain. (e) modelled PCM abundance (weight \%), with red hue indicating PCMs attributed to primary mineral weathering, and blue indicating PCMs attributed to other drivers (e.g., transformation of secondary minerals)

humid climates (Rasmussen et al. 2018a), but also illustrate that this correlation depends on the availability of primary minerals that can fuel active weathering. Consequently, within the broad envelope of humid climates, the capacity of PCMs to influence $\mathrm{SOC}$ is a function of geologic factors that locally enhance primary mineral abundance (e.g., parent material composition, landscape age, and topographic relief). Because enhanced weathering zones are limited in geographic extent, PCMs may explain less of 
the variation in SOC stocks at continental scales than previously argued; rather, their influence appears greatest at local or regional scales (Heckman et al. 2020; Nave et al. 2021). However, PCMs remain functionally important for SOC storage even when the total abundance of PCMs is low, given that PCMs and crystalline metal oxides account for a relatively constant fraction $(\sim 60 \%)$ of subsoil organic carbon in climates where precipitation exceeds evaporative demand (Kramer and Chadwick 2018). In combination with our results, this fact suggests that processes that maintain moderate levels of PCMs in weathered soils (e.g., Fe redox cycling) are likely important for the geography of SOC outside of enhanced weathering zones.

More broadly, our analysis suggests that the abundance of primary minerals controls poorly crystalline mineral abundance, and thus ultimately limits SOC storage across vast areas. Small changes in primary mineral abundance in weathered soils could alleviate limitation of PCM formation and enhance SOC storage. Specifically, our statistical model predicts that increasing feldspar $\mathrm{Al}$ by $1 \%$ of the soil mass would increase $\mathrm{Al}$ in PCMs by $20-41 \%$ (interquartile range) across the portion of the conterminous United States where precipitation exceeds evaporative demand. This implies that over long timescales, soil carbon storage outside of enhanced weathering zones might be affected by geologic processes than alter the flux of primary minerals to the soil (e.g., long distance dust transport), and may potentially be affected by human managed process that affect soil primary mineral stocks (e.g., soil erosion, or accelerated weathering geoengineering (Taylor et al. 2016)).

Finally, our model suggests that it is the weathering rate rather than the weathering state that proximately governs PCM abundance and SOC storage. The dependence of PCM stocks on the weathering rate implies that processes affecting mineral dissolution may potentially affect PCMs at relatively short timescales. The role of PCMs in the global carbon cycle thus depends on dynamic interactions between environmental drivers, weathering rates, PCM formation, and SOC cycling. To the extent that climate change influences weathering at short timescales (e.g., by altering soil hydrology, $\mathrm{pCO}_{2}$, or synthesis of organic acids), future climate dynamics may influence the mineralogical capacity of soils to store C. Forecasting and managing SOC effectively in the coming century will benefit from a more complete understanding of how quickly PCMs and associated SOC respond to environmental change.

Acknowledgements We thank Claire Kouba, Adam Davis, Lucas Janzen, and Katerina Georgiou for helpful suggestions. Research at LLNL was performed under the auspices of the DOE, Contract DE-AC52-07NA27344.

Author contributions Conceptualization: EWS, OAC, NS, EEN, JPR; Methodology, Investigation, and Visualization: EWS; Supervision: EEN, JPR; Writing-original draft: EWS; Writing - review \& editing: EWS, OAC, NS, EEN, JPR

Funding This study was supported by the U.S. Department of Energy (DOE), Office of Biological and Environmental Research, Genomic Science Program (GSP) Lawrence Livermore National Laboratory 'Microbes Persist' Soil Microbiome Scientific Focus Area SCW1632. Additional salary support for ES was provided by LLNL LDRD 19-ERD010. Research at LLNL was performed under the auspices of the DOE, Contract DE-AC52-07NA27344.

Data availability Derived data products (maps of mineral abundance) and code are available at Zenodo.org (https://doi. org/10.5281/zenodo.5098200). Instructions for accessing third party datasets needed for reproducing the analysis are included with the code.

\section{Declarations}

Conflict of interest The authors declare no competing interests.

Open Access This article is licensed under a Creative Commons Attribution 4.0 International License, which permits use, sharing, adaptation, distribution and reproduction in any medium or format, as long as you give appropriate credit to the original author(s) and the source, provide a link to the Creative Commons licence, and indicate if changes were made. The images or other third party material in this article are included in the article's Creative Commons licence, unless indicated otherwise in a credit line to the material. If material is not included in the article's Creative Commons licence and your intended use is not permitted by statutory regulation or exceeds the permitted use, you will need to obtain permission directly from the copyright holder. To view a copy of this licence, visit http://creativecommons.org/licenses/by/4.0/.

\section{References}

Barcellos D, O'Connell C, Silver W et al (2018) Hot spots and hot moments of soil moisture explain fluctuations in iron and carbon cycling in a humid tropical forest soil. Soil Syst 2:59. https://doi.org/10.3390/soilsystems2040059 
Bivand R, Keitt T, Rowlingson B (2020) rgdal: bindings for the "geospatial" data abstraction library. R package version $1.5-18$

Canty A, Ripley B (2020) boot: bootstrap R (S-Plus) functions. $\mathrm{R}$ package version 1.3-25

Chadwick OA, Gavenda RT, Kelly EF et al (2003) The impact of climate on the biogeochemical functioning of volcanic soils. Chem Geol 202:195-223. https://doi.org/10.1016/j. chemgeo.2002.09.001

Chen C, Barcellos D, Richter DD et al (2019) Redoximorphic Bt horizons of the Calhoun CZO soils exhibit depth-dependent iron-oxide crystallinity. J Soils Sediments 19:785-797. https://doi.org/10.1007/s11368-018-2068-2

Conant RT, Ryan MG, Ågren GI et al (2011) Temperature and soil organic matter decomposition rates-synthesis of current knowledge and a way forward. Glob Change Biol 17:3392-3404. https://doi.org/10.1111/j.1365-2486.2011. 02496.x

Coward EK, Thompson A, Plante AF (2018) Contrasting Fe speciation in two humid forest soils: insight into organomineral associations in redox-active environments. Geochim Cosmochim Acta 238:68-84. https://doi.org/10. 1016/j.gca.2018.07.007

Dahlgren RA (2015) Quantification of allophane and imogolite. In: Amonette JE, Stucki JW (eds) Quantitative methods in soil mineralogy. Soil Science Society of America, Madison, pp 430-451

Dahlgren RA, Boettinger JL, Huntington GL, Amundson RG (1997) Soil development along an elevational transect in the western Sierra Nevada, California. Geoderma 78:207-236. https://doi.org/10.1016/S00167061(97)00034-7

Davison AC, Hinkley DV (1997) Bootstrap methods and their application. Cambridge University Press, New York

Emad A, Bailey P (2017) wCorr: weighted correlations. R Package Version 1(9):1

Garcia Arredondo M, Lawrence CR, Schulz MS et al (2019) Root-driven weathering impacts on mineral-organic associations in deep soils over pedogenic time scales. Geochim Cosmochim Acta 263:68-84. https://doi.org/10.1016/j. gca.2019.07.030

Ginn B, Meile C, Wilmoth J et al (2017) Rapid iron reduction rates are stimulated by high-amplitude redox fluctuations in a tropical forest soil. Environ Sci Technol 51:3250-3259. https://doi.org/10.1021/acs.est.6b05709

Heckman K, Welty-Bernard A, Rasmussen C, Schwartz E (2009) Geologic controls of soil carbon cycling and microbial dynamics in temperate conifer forests. Chem Geol 267:12-23. https://doi.org/10.1016/j.chemgeo.2009. 01.004

Heckman KA, Nave LE, Bowman M et al (2020) Divergent controls on carbon concentration and persistence between forests and grasslands of the conterminous US. Biogeochemistry. https://doi.org/10.1007/s10533-020-00725-z

Hijmans R (2020) raster: geographic data analysis and modeling. $R$ package version 3.3-13

Jobbágy EG, Jackson RB (2000) The vertical distribution of soil organic carbon and its relation to climate and vegetation. Ecol Appl 10:423-436. https://doi.org/10.1890/10510761(2000)010[0423:TVDOSO]2.0.CO;2
Koenker R (2018) quantreg: quantile regression. R Package Version 5:38

Koenker R, Bassett G (1978) Regression quantiles. Econometrica 46:33. https://doi.org/10.2307/1913643

Kramer MG, Chadwick OA (2018) Climate-driven thresholds in reactive mineral retention of soil carbon at the global scale. Nat Clim Change 8:1104-1108. https://doi.org/10.1038/ s41558-018-0341-4

Maher K (2010) The dependence of chemical weathering rates on fluid residence time. Earth Planet Sci Lett 294:101-110. https://doi.org/10.1016/j.eps1.2010.03.010

Masiello CA, Chadwick OA, Southon J et al (2004) Weathering controls on mechanisms of carbon storage in grassland soils: weathering controls on carbon storage. Glob Biogeochem Cycles. https://doi.org/10.1029/2004GB002219

McCabe GJ, Wolock DM (2011) Independent effects of temperature and precipitation on modeled runoff in the conterminous United States: effects of temperature and precipitation on runoff. Water Resour Res. https://doi.org/ 10.1029/2011WR010630

Minasny B, Malone BP, McBratney AB et al (2017) Soil carbon 4 per mille. Geoderma 292:59-86. https://doi.org/10.1016/ j.geoderma.2017.01.002

Nave LE, Bowman M, Gallo A et al (2021) Patterns and predictors of soil organic carbon storage across a continentalscale network. Biogeochemistry. https://doi.org/10.1007/ s10533-020-00745-9

Prism Climate Group, Oregon State University (2011) Prism climate data

R Core Team (2020) R: A language and environment for statistical computing.

Rasmussen C, Heckman K, Wieder WR et al (2018a) Beyond clay: towards an improved set of variables for predicting soil organic matter content. Biogeochemistry 137:297-306. https://doi.org/10.1007/s10533-018-0424-3

Rasmussen C, Throckmorton H, Liles G et al (2018b) Controls on soil organic carbon partitioning and stabilization in the California Sierra Nevada. Soil Syst 2:41. https://doi.org/10. 3390/soilsystems2030041

Richter DB, Billings SA (2015) 'One physical system': Tansley's ecosystem as Earth's critical zone. New Phytol 206:900-912. https://doi.org/10.1111/nph.13338

Roberts DR, Bahn V, Ciuti S et al (2017) Cross-validation strategies for data with temporal, spatial, hierarchical, or phylogenetic structure. Ecography 40:913-929. https://doi. org/10.1111/ecog.02881

Rowley MC, Grand S, Verrecchia ÉP (2018) Calcium-mediated stabilisation of soil organic carbon. Biogeochemistry 137:27-49. https://doi.org/10.1007/s10533-017-0410-1

Schmidt MWI, Torn MS, Abiven S et al (2011) Persistence of soil organic matter as an ecosystem property. Nature 478:49-56. https://doi.org/10.1038/nature 10386

Schulze DG (2015) Differential X-ray diffraction analysis of soil minerals. In: Amonette JE, Stucki JW (eds) Quantitative methods in soil mineralogy. Soil Science Society of America, Madison, pp 412-429

Slessarev EW, Feng X, Bingham NL, Chadwick OA (2019) Landscape age as a major control on the geography of soil weathering. Glob Biogeochem Cycles 33:1513-1531. https://doi.org/10.1029/2019GB006266 
Smith DB, Cannon WF, Woodruff LG, Ellefsen KJ (2014) Geochemical and mineralogical maps for soils of the conterminous United States. US Geological Survey OpenFile Report 2014-1082

Taylor LL, Quirk J, Thorley RMS et al (2016) Enhanced weathering strategies for stabilizing climate and averting ocean acidification. Nat Clim Change 6:402-406. https:// doi.org/10.1038/nclimate2882

Torn MS, Trumbore SE, Chadwick OA et al (1997) Mineral control of soil organic carbon storage and turnover. Nature 389:170-173. https://doi.org/10.1038/38260

von Fromm SF, Hoyt AM, Lange M, Acquah GE, Aynekulu E, Berhe AA, Haefele SM, McGrath SP, Shepherd KD, Sila AM, Six J, Towett EK, Trumbore SE, Vågen TG, Weullow E, Winowiecki LA, Doetterl S (2021) Continental-scale controls on soil organic carbon across sub-Saharan Africa. Soil 7:305-332. https://doi.org/10.5194/soil-7-305-2021.

Wang X, Yoo K, Mudd SM et al (2018) Storage and export of soil carbon and mineral surface area along an erosional gradient in the Sierra Nevada, California. Geoderma 321:151-163. https://doi.org/10.1016/j.geoderma.2018.02. 008

Wills S, Loecke T, Sequeira C et al (2014) Overview of the U.S. rapid carbon assessment project: sampling design, initial summary and uncertainty estimates. In: Hartemink AE, McSweeney K (eds) Soil carbon. Springer International Publishing, Cham, pp 95-104

Yu F, Hunt AG (2017) Damköhler number input to transportlimited chemical weathering calculations. ACS Earth Space Chem 1:30-38. https://doi.org/10.1021/ acsearthspacechem.6b00007

Publisher's Note Springer Nature remains neutral with regard to jurisdictional claims in published maps and institutional affiliations. 